\title{
SCAR OR BLEMISH? \\ INVESTIGATING THE LONG-TERM IMPACT OF INVOLUNTARY JOB LOSS ON HEALTH
}

Mathis Schröder 


\section{Scar or Blemish? Investigating the Long- Term Impact of Involuntary Job Loss on Health}

Mathis Schröder

\subsection{Job loss - a risk for individual wellbeing}

Job loss is one of the most undesirable events for an individual, as it may affect a person's wellbeing negatively on a multitude of dimensions. There may be direct and indirect effects of job loss on wellbeing, and these effects may be temporary or permanent, depending on the outcome of interest. Ruhm (1991) and Jacobson, LaLonde, and Sullivan (1993) for example show that wage earnings - not surprisingly - decline dramatically in the event of a job loss. However, this effect is permanent in the sense that a comparable group without a job loss follows a much higher wage path in the years following the job loss. Effects on family life have also been shown: Charles and Stephens (2004) find a significant increase in divorce probability for laid-off individuals. Bono, Weber, and Winter-Ebmer (2008) show that fertility decisions are changed due to a job loss, resulting in delayed or forgone child birth. Various papers find a negative effect of job loss on health. Clearly, health is an example where an indirect effect can be imagined - through lower wages, investments in health are declining, and then overall health is affected in addition to a possible direct effect (through depressive symptoms caused by the unemployment situation, for example). Sullivan and von Wachter (2009) find an increase in mortality, Strully (2009) shows that there are effects on subjective health measures as well. Others, for example Salm (2009) or Browning et al (2006), argue that health effects are rather spurious and not necessarily caused by the job loss. Long-term effects on health have not yet been investigated, mainly due to lack of suitable data.

One common problem in the literature on involuntary job loss is the direction of causality: if people are less productive, they will lose their job and then are likely to earn less in the future. A similar argument holds for deteriorating health, which might lead to a loss of the job in the first place. A solution to this issue is to find reasons for the job loss, which are not linked to the outcome variable. The literature cited above uses the common approach of "displaced" workers to (arguably) solve this problem. A displaced worker is a worker who has lost his job due to a plant closure, where the plant is sufficiently large for the individual worker not to matter much in the closure (Ruhm, 1991; Jacobson, LaLonde, and Sullivan, 1993; Sullivan and von Wachter, 2009). In this case, the individual's influence is not enough to cause the closure, but the closure affects all those losing their job in 
the same way. Even though this approach may not be perfect, it is the closest way to disentangle the individual reasons for job loss from a common and thus exogenous one.

The effects of an exogenous involuntary job loss, however, do not only depend on the loss of the job itself, but to a potentially large extent also on the institutional settings in the background. In a system with mandatory complete health insurance coverage, one would expect the effects of job loss on health to be less severe than in a system which only provides health insurance coverage through the employer. Institutional settings may also shorten the duration in unemployment after job loss, which could be positive or negative on wages - a higher match quality may take more time to be found but lead to higher wages, but a long lasting unemployment support may lead to larger human capital depreciation. Where a family is supported - financially or otherwise - independent of employment of its members, a spell of unemployment may have less influence on fertility or marriage decisions.

This paper uses the SHARELIFE data to investigate the long term effects of job loss on health, exemplified through three health outcomes, to test whether health effects last or are only temporary. The effects of job loss due to displacement are compared to those which are related to lay-off or firing to test whether there are notable differences. Finally, a country's institutional settings related to the labour market are considered in their influences on individuals' long term health. SHARELIFE is especially useful for this project, as it allows for the first time to relate events in a person's life course (here: involuntary job loss) to long term outcomes (here: health). A combination of SHARELIFE data with SHARE data from waves 1 and 2 is used for a full set of control variables.

The next section provides a review of the literature. Section 3 defines the sample, explains the measurements of the outcome variables and introduces the institutional variables that are used in this analysis. Section 4 then shows the analyses, whereas section 5 briefly summarizes.

\subsection{Literature findings on job loss and wellbeing}

Ruhm (1991) uses five waves of the Panel Study of Income Dynamics (PSID) to investigate the effect of job loss on unemployment probability and wages. Applying a definition of mass layoffs and plant closures for displacement, he finds that while the unemployment probability in the following five years is not affected by displacement, wages are permanently lower by 10-13 percent compared to those workers not displaced. In a similar study, Jacobson, LaLonde, and Sullivan (1993) use administrative data from the US federal state of Pennsylvania to elicit the effects of mass-layoffs on wages of high-tenured workers. They find losses in earnings of about 25 percent compared to pre-displacement earnings even six years after the job was lost. 
Sullivan and von Wachter (2009) employ the same Pennsylvania dataset to investigate how the health of these workers has suffered from displacement. In linking their sample to administrative death records they are able to test whether the mortality of displaced workers is increased after job loss. Indeed they find that mortality rates for the displaced workers are 50\%-100\% higher than for the nondisplaced. Strully (2009) uses three waves of the PSID (1999, 2001, 2003) when looking at the relationship of health and job loss. She distinguishes between several different job loss categories, allowing for no-fault, fired or laid off, voluntary, or other types of job loss. In a first step, Strully then relates health prior to the job loss to the job loss category and finds that while those fired or laid off are in worse health prior to the job loss, a no-fault job loss is not associated with bad prior health, which is taken as support for the exogeneity of plant closure and health. She reports that while the short-term effects for fired individuals are stronger on self-rated health, they are still substantial and significant for those with a no-fault job loss, suggesting that job loss is associated with worse health.

There are also some findings in the literature that question the effects of job loss on health. Salm (2009) looks at the health of individuals experiencing a job loss in the US with the Health and Retirement Study (HRS). He is able to look at objective as well as subjective measures of health by different reasons of job loss. He does not find any effect of plant closure or of being laid off on health, only not surprisingly - when people leave for health reasons, their health deteriorates in the subsequent periods. The sample of investigation, however, consists only of older individuals and therefore the number of people "under treatment" of displacement is rather small. Browning, Moller Dano, and Heinesen (2006) investigate how job loss is associated with medical stress indicators. They use a $10 \%$ random sample of the Danish male population and link these records to business and hospital records. They report that displacement does not cause hospitalization for stress-related illnesses for various definitions of displacement. They speculate that this finding may be related to the generous welfare scheme in Denmark compared to the United States. In another study of European administrative data, Eliason and Storrie (2009) look at the Swedish case and observe a higher mortality of those who are displaced in Sweden - thus contradicting the effects Browning et al find in a country that at least from the outset is very similar to Denmark.

This chapter explores the possibilities of advancing the literature on two fronts: first, we analyze true long-term health effects after job loss. The SHARELIFE sample allows looking at individuals whose job changes have happened up to 50 years prior to the current health measures. This gives a new perspective on the consequences of involuntary job loss on health. In addition, for the first time we are able to compare the effects of displacement across a number of European countries, which allows investigating the influence of the institutional settings in these countries regarding the treatment of the unemployed. While the comparison of the previous studies across countries is difficult because the measures are different both for displacement and health, the ex-ante harmonization in the 
SHARELIFE countries guarantees that there are no such issues: the questions and health measures are identical across all participating countries.

\subsection{Job loss and health in the SHARELIFE sample}

This paper uses SHARELIFE data, but augments it with the data from waves 1 and 2 from SHARE. Similar to the literature cited above, there are several restrictions to the sample, which are necessary to make sure that the effects found are not due to sample composition. The first selection has to be on those individuals who are at risk of losing their jobs due to displacement, which, obviously, rules those out who have never been employed. Furthermore, since civil servants and military personnel usually do not face the risk of a business closure, these are excluded from the analysis. Although self-employed face the risk of displacement, they are excluded in the analyses, because a business closure can be caused by their behaviour, and thus the causation of displacement on outcome is not (as) clear. In addition, as the agricultural sector has usually a lot more day-to-day workers and less stable employment, all individuals in this sector are left out.

There are a number of other restrictions to ensure that the analysis is sound. Only individuals between 50 and 90 years of age at the point of the third interview are considered, although the findings are robust against changes in this variable. To not be biased by individuals who change their jobs after training, the minimum age at job change is 20 , whereas no person displaced after 60 is still in the data to avoid confounding effects with retirement decisions. To avoid effects of the depression and war era, only job changes after 1950 are used, and to avoid effects correlating with SHARE wave 1 and 2, only displacement up to 2004 are considered. Individuals of the former German Democratic Republic, of the Czech Republic and of Poland are not considered in the analysis, as they did not have comparable conditions before and after the fall of the communist countries. As events are sometimes a long time ago for these respondents, individuals with low cognitive ability (as measured in wave 2 of SHARE) are excluded.

There are two sets of individual explanatory variables: the first is to control for differences prior to job change. These include childhood variables, specifically health as a child, access to health care as a child, school performance, amenities at home, people per room, whether the home was private or not, and - as a measure for socio economic status of the parents - whether there were enough books to fill one shelf in the house at age 10. Variables prior to job change also include the years of education, occupation and industry indicators, and some parental characteristics. Job and industry characteristics are taken from the first job a person had to avoid confounding effects that may have come after job loss. The second set provides contemporary information in order to correct for differences at the point of the interview which are not influenced by displacement. These are age and gender, and - unless noted otherwise - country fixed effects. 
The central explanatory variable is the one defining involuntary job loss and the comparison category. The variable RE031, which is asked for all job spells a person reports, provides an intuitive definition of three types of job changers (one voluntary, two involuntary):

1. those who always changed their job on their own account and thus always voluntary,

2. those who were at least once laid off and never experienced a business closure, and

3. those who have at least once lost their job because of a plant closure.

In the analysis, the comparisons always use the voluntary changers as a benchmark for the other two groups, with the expectation that group (1) fares better than group (2) and (3), while the effects for group (2) are expected to be larger than for group (3) because of the before mentioned issues of causality.

The analyses are restricted to the following outcome variables - self-perceived health, defined as being in poor or fair health, having at least one chronic disease and having at least one depressive symptom as measured via the EURO-D scale in wave 2 of SHARE. This spread provides a nice overview of subjective, objective and mental health, thus covering a wide range of individual health measures. The effects of job loss depend on the institutional settings and on how well the individual is caught in the safety net the institutions provide. For this paper, the concentration is on the unemployment benefit structure that each country had in 2007, where four dimensions are considered: the replacement rate, the duration of payment, the qualifying conditions and the employee contributions. Assuming that the changes over time are not dramatic, using the current setting as a proxy adjusts reasonably well for the institutional background at the time of the job loss.

Figure 17.1 shows the differences in self perceived health comparing those losing their job involuntarily and those who change voluntarily, split by country. While the substantial differences in reported health across countries also depend on the reporting style (Jürges, 2007), the differences within a country show an interesting variation over Europe: in Sweden, for example, the difference in health between voluntary and involuntary job changers is basically non-existent, whereas in Germany or Austria, those who suffer from involuntary job change are much more likely to report bad health. This variation in within-country differences may be partially driven by how well the institutional settings (i.e. the respective unemployment benefit system) are able to help the individual when coping with unemployment.

Figure 17.1: Fraction Reporting Poor or Fair Health by Job Change Status 


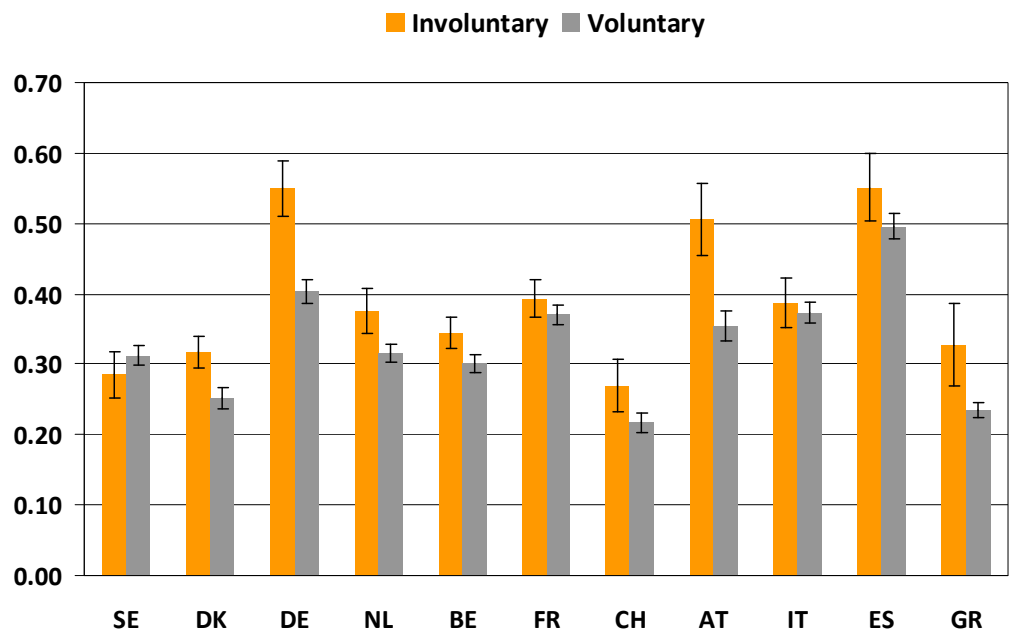

\subsection{The analysis of job loss and health}

Before turning to the actual analysis of the effects of job loss on health, we first have to consider how involuntary job loss is related to health prior to that event the approach Strully (2009) used as evidence that job displacement is exogenous to health. Childhood health is used here as a proxy for health prior to job loss. The bars in figure 17.2 represent regressions of the likelihood of involuntary job loss on an indicator of childhood health, thus comparing the two groups with involuntary job loss separately to those who always changed their job on their own account. Regressions with robust standard errors were run separately for men and women, the error bars reflect the 95\% confidence intervals around the coefficients of health on job loss.

Even though childhood health is a retrospective measurement and thus clearly influenced by the respondents' current situation, the relationship shown in figure 17.2 is similar to what Strully finds in her analysis with a clear difference in the two groups: there are no effects of childhood health on the likelihood of being in the group of those suffering from plant closures (group 3), while reporting good or better childhood health reduces the likelihood of being in the group of those suffering from layoff or firing significantly (10\% level). Although the effects are slightly smaller for women, there is no difference in the qualitative results.

The analysis now turns to the issue of displacement and health in the current situation. As mentioned above, we will look at three different health indicators: current self perceived health status ( 1 if fair or poor), chronic diseases ( 1 if at least one disease), and depression ( 1 if at least one symptom mentioned). We are interested in how these health indicators vary with the job change history - how do 
those who are displaced or fired fare compared to those who never had this experience? Figure 17.3 shows the coefficients from regressions run separately by gender of the respective health variable on the indicators for displacement (group 3 above) and lay-off (group 2), controlling for the wide range of variables mentioned in section 17.2, i.e. demographic, childhood and parental characteristics as well as industry, occupation and country indicators. Hence we will tease out the differential effect of involuntary job loss by group compared to those never suffering from involuntary job loss. (The bivariate regressions did not lead to qualitatively different results and are thus not reported here.) The error bars again reflect the $95 \%$ confidence interval around the coefficients from a regression with robust standard errors.

Figure 17.2: Childhood Health in Relation to Job Change Reasons

Bivariate Full Model

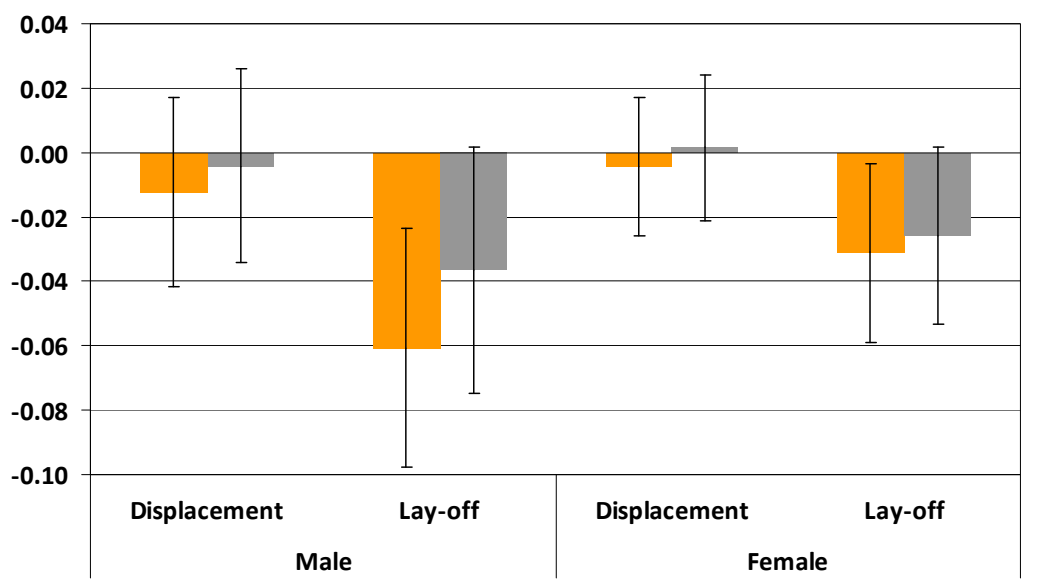

The essential message in Figure 17.3 is that both groups suffering from involuntary job loss are in worse health compared to those who never experience a displacement or a lay-off. However, one can also see small differences between the groups: those who were displaced show smaller effects, which also are not always significant at the $95 \%$ level. This is in line with what was postulated before health and lay-offs may be intertwined, such that bad health causes the lay-off initially at least for some cases, which leads to larger effects here. Displacement does not seem to relate to chronic diseases for men, while for females having suffered from lay-offs has a positive correlation with having chronic diseases. While females have slightly stronger effects on self reported health and chronic diseases, men seem to suffer more from depressions following an involuntary job loss. These gender differences are not significant, however. 
Figure 17.3: Current Health in Relation to Involuntary Job Loss

Health Poor/Fair $\square$ Any Chronic Symptoms Any Depressive Symptoms

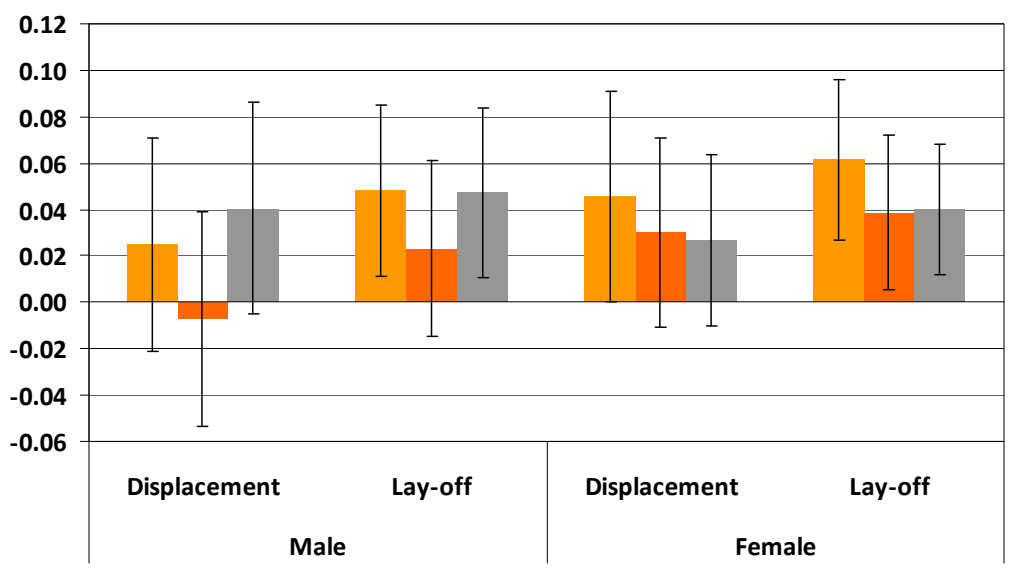

\subsection{Influences of the welfare state}

We now turn to the analysis of how the welfare state structure affects the current health of those individuals who have either been displaced or fired. We have seen the differences in health reports between involuntary and voluntary job changers in figure 17.1, and those differences across countries could have their reason in the institutional backgrounds of each country. Table 1 shows the current (2007) rules of unemployment benefits, where we specifically consider the replacement rate measured as the ratio to previous income, the duration of benefit payments, the qualifying conditions measured as the ratio of weeks an individual has to contribute to the system over the past year, and lastly the employee contribution as a percentage of income. (This table is a strong simplification of the reality in an attempt to put all countries into a common framework. The calculation of duration of benefits is partly based on weeks and thus produces "odd" numbers.) When looking at the welfare state variables, a clear-cut prediction of how they should influence the health of the unemployed is not clear - a more lenient welfare system could produce better health, but also in the long run it could lead to individuals less satisfied with their health.

The regression analysis using the unemployment benefit structure assumes that the combination of these measures is meant to help the individual reduce the negative effects of unemployment and thus aims at assessing the joint effect of these measures. For the purpose of evaluation, we now leave out the country fixed effects in the following regressions, and instead include the welfare state variables. 
However, all other control variables mentioned above are still included in the model, which again is estimated with robust standard errors.

Since the previous analyses have shown that the differences between those displaced and those suffering from lay-off are small, we now return to the beginning and split the sample into those with an involuntary job change and those who changed voluntarily, i.e. group 1 compared to the combination of groups 2 and 3 (a separate regression did not yield different results). Each of the four welfare state variables in table 17.1 are considered as explanatory variables as well as their differential influence (via interaction terms) on those who lost their jobs involuntarily. For reasons of brevity, the only dependent variable considered here is selfreported health. However, we calculate the effects separately for men and women. In order to elicit the effect of the welfare state on health for those who have lost their job, we use the coefficients of the interaction terms, calculate the effect of each welfare state variable at its respective country mean and then sum over all effects. Hence, we calculate the joint differential effect of replacement rate, duration of benefits, qualifying ratio, and employee contributions on the health of those suffering from involuntary job loss.

Table 3.1: $\quad$ Unemployment Benefit System Variables by Country

\begin{tabular}{lrrrr}
\hline & & & & \\
& Duration of & Employee \\
Replacement & Renefits & Qualifying & rontribution \\
(Months) & Ratio & (\%) \\
\hline SE & 0.70 & 9.9 & 1 & 0.00 \\
DK & 0.90 & 12.0 & 17 & 8.00 \\
DE & 0.67 & 12.0 & 17 & 3.25 \\
NL & 0.70 & 24.0 & 35 & 0.00 \\
BE & 0.60 & 12.0 & 30 & 0.87 \\
FR & 0.66 & 40.0 & 14 & 2.00 \\
CH & 0.70 & 13.2 & 26 & 1.00 \\
AT & 0.55 & 12.0 & 28 & 3.00 \\
IT & 0.30 & 7.0 & 26 & 0.00 \\
ES & 0.70 & 6.0 & 9 & 1.55 \\
GR & 0.40 & 8.3 & 16 & 1.33 \\
\hline
\end{tabular}


Results are shown in Figure 17.4 separately for men and women, where each bar shows the joint differential effect of the welfare state variables on the likelihood to be in bad health for those who report having had any involuntary job loss. In both regressions, the hypothesis that the welfare state variables do not have any explanatory power has to be rejected (at $5 \%$ level), however, the joint differential effect is only significant for females. This is reflected in figure 17.4, showing much larger effects for women reporting involuntary job loss than men. The effect is clearly positive for women, as the likelihood to be in bad health is reduced in every country except Denmark by at least $10 \%$. For men, only in Denmark we see an effect that is estimated to be larger than a 5\% reduction in the likelihood to be in bad health. The gender difference may be in part a (positive) selection effect for the period under consideration: while men were in general the main breadwinners and thus had to stay in the labour market, women who lost their job involuntarily and stayed in the labour market despite possible outside options such as marriage or childbirth, may have been in better health. However, since we control for childhood health, this effect would have to be rather strong.

Figure 17.4: Differential effect of unemployment benefits on health, by gender

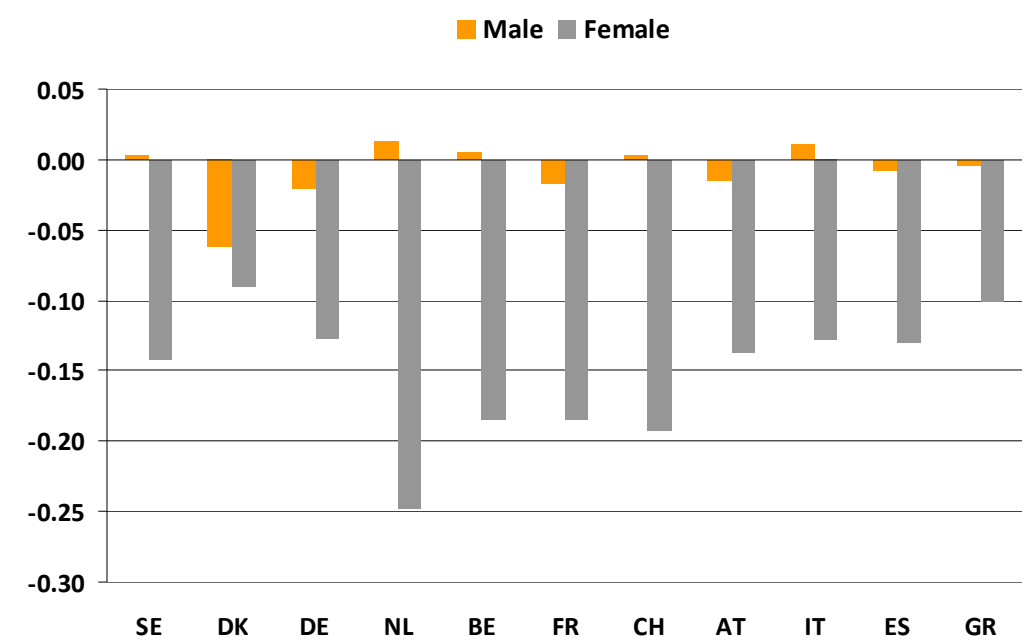

\subsection{Summary}

This paper shows that there are long term effects of involuntary job changes on health. Both individuals reporting that they were laid off and those reporting to have lost their jobs due to plant closures are in worse health than those individuals never experiencing lay-offs or displacement. This holds true for three different 
health indicators: self-perceived health, chronic diseases, and depressive symptoms. It is likely, that the sample analysed here suffers from a survivor bias: individuals who have suffered greatly from a job loss may already have died. However, this would bias the results towards zero, such that the observed effects may in reality be even stronger.

Men and women are almost equally affected by an involuntary job loss in terms of health, although women experience slightly stronger effects. In part, this may be due to a selection into the workforce - women in the age group considered may have had substantially different motives to work, which the control variables are not able to pick up.

The differential effects of the unemployment benefit system on the health of those with involuntary job loss have to be considered with care, because of the simplifications mentioned and also because their inclusion may also pick up pure state variation. However, the difference between men and women is of interest controlling for age, occupation, industry and socio-demographic background variables, it seems as if the welfare state has particularly helped women in reducing negative effects of involuntary job loss on health.

\section{References}

Bono, Emilia del, Andrea Weber and Rudolf Winter-Ebmer, 2008. "Clash of Career and Family: Fertility Decisions After Job Displacement". Centre for Economic Policy Research, Discussion Paper No. 6719, London.

Browning, Martin, Anne Moller Dano and Eskil Heinesen, 2006. "Job Displacement and StressRelated Health Outcomes". Health Economics, Vol. 15, pp. 1061-1075.

Charles, Kerwin Kofi and Melvin Stephens Jr., 2004. "Job Displacement, Disability, and Divorce“. Journal of Labor Economics, 2004, Vol. 22(2), pp. 489-522.

Eliason, Marcus and Donald Storrie, 2009. "Does Job Loss Shorten Life?" The Journal of Human Resources, Vol. 44 (2), pp 277-302.

Jacobson, L., R. LaLonde, and D. Sullivan.1993 "Earnings Losses of Displaced Workers". American Economic Review, Vol. 83(4), pp. 685-709.

Jürges, Hendrik, 2007. "True health vs. response styles: Exploring cross-country differences in self-reported health". Health Economics, Vol. 16(2), pp. 163-178.

Ruhm, C. 1991. “Are Workers Permanently Scarred by Job Displacement?” American Economic Review, Vol. 81(1), pp. 319-324.

Salm, Martin, 2009. "Does Job Loss Cause Ill Health?" Health Economics, Vol. 18, pp. 10751089.

Strully, Kate W., 2009. "Job Loss and Health in the U.S. Labor Market". Demography, Vol. 46(2), pp. 221-246.

Sullivan, Daniel and Till von Wachter, 2009. "Job Displacement and Mortality: An Analysis using Administrative Data". The Quarterly Journal of Economics, Vol. 124(3), pp. 1265-1306. 